\title{
Assessing the performance of troposphere tomographic modeling using multi-source water vapor data during Hong Kong's rainy season from May to October 2013
}

\author{
Biyan Chen and Zhizhao Liu \\ Department of Land Surveying \& Geo-Informatics, Hong Kong Polytechnic University, Hong Kong, China \\ Correspondence to: Zhizhao Liu (1szzliu@polyu.edu.hk)
}

Received: 8 May 2016 - Published in Atmos. Meas. Tech. Discuss.: 22 July 2016

Revised: 12 October 2016 - Accepted: 14 October 2016 - Published: 28 October 2016

\begin{abstract}
Acquiring accurate atmospheric water vapor spatial information remains one of the most challenging tasks in meteorology. The tomographic technique is a powerful tool for modeling atmospheric water vapor and monitoring the water vapor spatial and temporal distribution/variation information. This paper presents a study on the monitoring of water vapor variations using tomographic techniques based on multi-source water vapor data, including GPS (Global Positioning System), radiosonde, WVR (water vapor radiometer), NWP (numerical weather prediction), AERONET (AErosol RObotic NETwork) sun photometer and synoptic station measurements. An extensive investigation has been carried out using multi-source data collected from May to October 2013 in Hong Kong. With the use of radiosonde observed profiles, five different vertical a priori information schemes were designed and examined. Analysis results revealed that the best vertical constraint is to employ the average radiosonde profiles over the 3 days prior to the tomographic time and that the assimilation of multi-source data can increase the tomography modeling accuracy. Based on the best vertical a priori information scheme, comparisons of slant wet delay (SWD) measurements between GPS data and multi-observational tomography showed that the root mean square error (RMSE) of their differences is $10.85 \mathrm{~mm}$. Multi-observational tomography achieved an accuracy of $7.13 \mathrm{~mm} \mathrm{~km}^{-1}$ when compared with radiosonde wet refractivity observations. The vertical layer tomographic modeling accuracy was also assessed using radiosonde water vapor profiles. An accuracy of $11.44 \mathrm{~mm} \mathrm{~km}^{-1}$ at the lowest layer $(0-0.4 \mathrm{~km})$ and an RMSE of $3.30 \mathrm{~mm} \mathrm{~km}^{-1}$ at the uppermost layer $(7.5-8.5 \mathrm{~km})$ were yielded. At last, a test of the tomographic modeling in a torrential storm occurring on
\end{abstract}

21-22 May 2013 in Hong Kong demonstrated that the tomographic modeling is very robust, even during severe precipitation conditions.

\section{Introduction}

Water vapor is a powerful greenhouse gas in the earth's atmosphere and plays an important role in many atmospheric processes. It contributes significantly to the formation of many weather phenomena such as cloud, rain, snow, sleet, hail and other precipitation. A small amount of water vapor variation may cause severe weather changes (Mohanakumar, 2008). Accurate information of water vapor spatiotemporal distributions is thus crucially important for weather forecasting services and meteorological research, such as precipitation and severe weather forecasting, and natural hazard mitigation (Bender and Raabe, 2007; Perler et al., 2011; Rocken et al., 1997). However, atmospheric water vapor remains one of the most poorly characterized parameters in meteorology due to its highly variable nature in space and time (Lee et al., 2013; Rocken et al., 1997).

Over the past years, many techniques have been developed to improve the observation of atmospheric water vapor, including both ground-based observation systems and satelliteborne remote sensing sensors (Guiraud et al., 1979; Elgered et al., 1991; Holben et al., 2001; Niell et al., 2001; Gao and Kaufman, 2003). Among various platforms, Global Navigation Satellite System (GNSS) has been considered as a powerful approach to retrieve atmospheric water vapor data with high spatial and temporal resolutions. In addition, GNSS also has the advantages of low operational cost and all-weather 
capability when compared to other traditional means. For example, limited by the high expense of launching weather balloons, there are only about 850 radiosonde sites globally, and radiosonde measurements are usually only made twice per day at most stations (Kuo et al., 2005; Niell et al., 2001). The poor regional coverage and low temporal resolution of the radiosonde observations significantly limit their values in many applications such as weather forecasting. Another important instrument for water vapor measurement is the water vapor radiometer (WVR) that has often been used to correct tropospheric wet delay in geodetic observations such as very-longbaseline interferometry (VLBI) (Beckman, 1985; Elgered et al., 1991). However, the WVR is sensitive to weather conditions, and large uncertainties may exist when observation is made in rainy or foggy conditions. The strengths of GNSS in atmospheric sounding have significantly facilitated the development of GNSS meteorology, which has become a focus of multidisciplinary research in the fields of meteorology and space geodesy.

The concept of GNSS meteorology was first documented in Bevis et al. (1992) in which the possibilities of Global Positioning System (GPS) remote sensing of atmospheric water vapor were elaborated. Thereafter numerous field campaigns demonstrated the GPS/GNSS ability to accurately measure atmospheric water vapor, and the derived precipitable water vapor (PWV) data can reach an accuracy of 1-2 $\mathrm{mm}$ or even better (Duan et al., 1996; Elgered et al., 1997; Lee et al., 2013; Liu and Li, 2013; Rocken et al., 1993; Tregoning et al., 1998). GNSS-inferred PWV data have enriched meteorological research by providing detailed information of horizontal distribution of atmospheric water vapor. However, the vertical profile information remains unknown. Inspired by the capability of the tomography technique of reconstructing the three-dimensional (3-D) field, Bevis et al. (1992) also envisioned the potential of tomographic technique in the reconstruction of 3-D water vapor distribution using GPS-derived slant wet delay (SWD) data. In 2000, Flores et al. (2000) performed an experiment of water vapor tomography based on a GPS network in Hawaii, USA. This was the first time that the tomographic technique was demonstrated to reconstruct 3-D structure of tropospheric water vapor. After this successful experiment, more work in tropospheric tomography has been carried out in the GPS/geodesy community (Champollion et al., 2005; Bender and Raabe, 2007; Rohm and Bosy, 2009, 2011; Notarpietro et al., 2011; Perler et al., 2011; Bender et al., 2011). Bi et al. (2006) carried out a water vapor tomography experiment by using a small GPS network in the Beijing region. The accuracy of wet refractivity profiles from tomographic solution can reach $\sim 7 \mathrm{~mm} \mathrm{~km}^{-1}$ by comparing them with radiosonde ones. Troller et al. (2006) investigated the tomographic technique using GPS observations from the Swiss national GPS network AGNES of the Swiss Federal Office of Topography. Comparisons of water vapor profiles between tomography and numerical weather models showed that the root mean square error (RMSE) can reach an order of better than $10 \mathrm{~mm} \mathrm{~km}^{-1}$. Xia et al. (2013) presented a study for water vapor tomography using GPS observations and radio occultation profiles. An overall accuracy of $6.3 \mathrm{~mm} \mathrm{~km}^{-1}$ of tomographic results is achieved for a 10-day test. In the research reported by Shangguan et al. (2013), GPS tomography results in a whole year 2007 were evaluated using radiosonde data, and a wet refractivity field of accuracy of 6.5$9.0 \mathrm{~mm} \mathrm{~km}^{-1}$ is obtained. A 1-year tomography experiment in Hong Kong was carried out by Jiang et al. (2014), in which a tomographic result of accuracy of $\sim 7.9 \mathrm{~mm} \mathrm{~km}^{-1}$ was obtained when compared with radiosonde data.

However, some limitations in the tomographic technique still have not been resolved (Bender et al., 2009; Bender and Raabe, 2007; Rohm et al., 2014). In the tomographic approach, the probed space is usually discretized into a number of 3-D closed voxels. Water vapor quantity in each voxel can then be estimated from a large number of integral water vapor ray paths using the tomographic technique. This requires each voxel to be crossed by a number of GNSS signals from different directions. In practice, this requirement is hardly satisfied because of the following: (1) most GNSS networks are not dedicatedly designed for tomography purposes. Ensuring that each voxel is being crossed by GNSS signals requires a high density of GNSS receivers in the network, which is practically impossible for cost and operational reasons. (2) At present, the number of trackable GNSS satellites during a tomographic period is limited, which restricts the number of rays that cross through the voxels; this situation is expected to improve with the launch of more satellites in Beidou and Galileo navigation satellite systems. (3) Water vapor is highly variable in both spatial and temporal domains; thus the voxel size should not be too large spatially, and the tomographic period should not be too long temporally. As a result, it is almost impossible to tomographically reconstruct a 3-D water vapor field by using GNSS data alone. This problem can be resolved by adding inter-voxel constraints and especially by introducing non-GNSS measurements (Bender and Raabe, 2007; Bevis et al., 1992). Several studies have shown that GNSS tropospheric tomography has improved after assimilating other observations, such as by radiosondes (Bi et al., 2006; Skone and Hoyle, 2005), numerical weather prediction (NWP) (Notarpietro et al., 2011) and radio occultation (Xia et al., 2013).

In the past studies, the type of water vapor data sources used in tomography is still very limited, usually from one single type of water vapor observation technique. In this study, we will investigate the tomographic technique by assimilating water vapor measurements from six sources available in the Hong Kong region. In addition to GPS, water vapor data from five other sources are also used, namely from radiosondes, the WVR, NWP, the AErosol RObotic NETwork (AERONET) sun photometer and synoptic stations. Radiosonde water vapor data provide excellent vertical profile observation information, which is crucial for tomographic modeling. The availability of abundant non-GNSS 


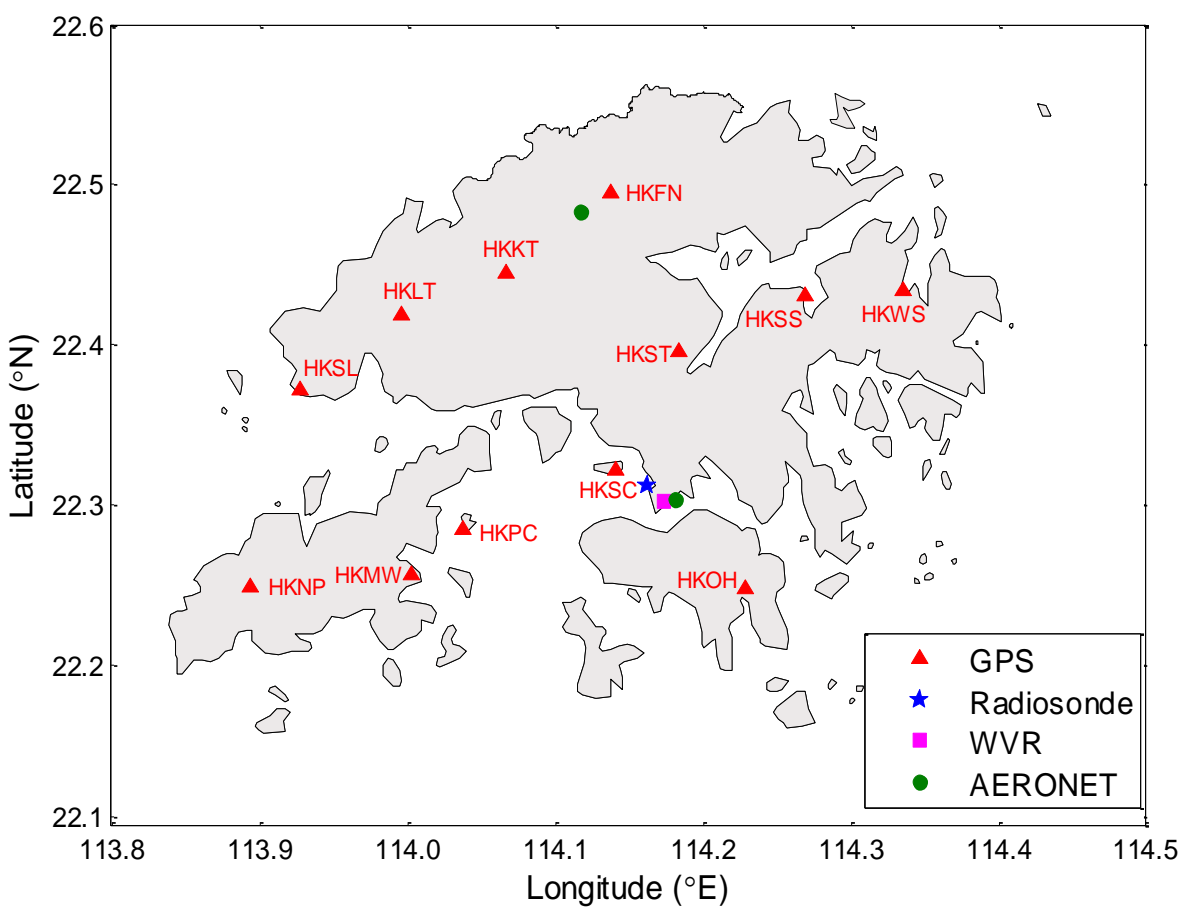

Figure 1. Geographical distribution of GPS, radiosonde, WVR and AERONET stations in Hong Kong.

data that are of different characteristics offers us the opportunity to examine their contribution to water vapor tomography results. In this study, we will investigate approaches of how to properly assimilate these data into the tomographic model. Five schemes that contain different vertical a priori information are designed and examined. The performance of the multi-observational tomography is fully evaluated using GNSS data and radiosonde profiles. In addition, the tomographic results are applied to reveal the evolution of the water vapor field during heavy precipitation events. This paper is structured as follows. Section 2 provides an overview of multiple water vapor observation systems in Hong Kong. A description of the principle of water vapor tomography with multi-source data is presented in Sect. 3. Section 4 is dedicated to the evaluation of the performance of water vapor tomography. Conclusions and final remarks are given in Sect. 5 .

\section{Description of tomography inputs}

In this study, water vapor data for tomographic modeling are obtained from GPS, radiosonde, WVR, NWP, AERONET and synoptic station measurements. Figure 1 shows the geographical distribution of GPS, radiosonde, WVR and AERONET stations in Hong Kong. Actually, the synoptic stations are co-located with the GPS stations (a total of 12 stations). Each GPS station is equipped with meteorological instruments to record air pressure, temperature and relative humidity. Refractivity computed from these parameters (more details in Sect. 3) can be used as good input data in the tomography.

\subsection{GPS observations}

The Lands Department of the Government of Hong Kong Special Administrative Region (HKSAR) has been operating the GPS network - Hong Kong Satellite Positioning Reference Station Network (SatRef) since 2000 (Chan and Li, 2007). Before 2015, this network consists of 12 GPS stations, and their locations are shown in Fig. 1. GPS signals are significantly affected when they traverse the neutral atmosphere. The tropospheric path delay is a major error source in GPS precise positioning. Usually, the tropospheric delay can be divided into hydrostatic and wet components, and the wet component can be estimated together with GPS coordinate parameters. Currently, many GNSS data processing software packages are capable of accurately estimating the tropospheric delay. In this study, we adopt the Bernese GNSS software to process the GPS data. This software uses doubledifference to remove the satellite and receiver clock biases, and outputs many products including zenith tropospheric delay (ZTD), gradients and the double-differenced residuals (Dach et al., 2007). The slant wet delays can thus be retrieved according to Chen and Liu (2014): 


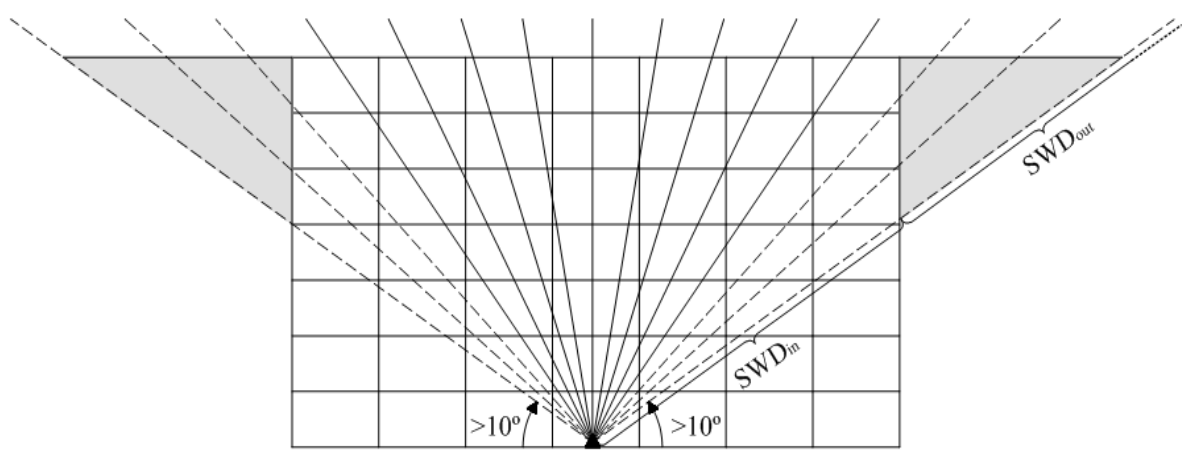

Figure 2. Schematic diagram of rays used in the tomography. The rectangle defines the tomographic region. Normally, only rays (in solid lines) that enter the tomographic model from the top layer can be used, and rays (in dashed lines) entering from the laterals should be rejected.

$$
\begin{aligned}
\mathrm{SWD}= & (\mathrm{ZTD}-\mathrm{ZHD}) \cdot f(z)+\frac{\partial f}{\partial z} \\
& \left(G_{\mathrm{N}, \mathrm{W}} \cdot \cos (\phi)+G_{\mathrm{E}, \mathrm{W}} \cdot \sin (\phi)\right)+R,
\end{aligned}
$$

where ZHD is the zenith hydrostatic delay, which can be accurately modeled with surface meteorological observations. $z$ and $\phi$ are satellite zenith distance and azimuth angle, respectively. $f$ is the wet mapping function. In our GNSS data processing, the wet Niell mapping function (Niell, 1996) is used. $G_{\mathrm{N}, \mathrm{W}}$ and $G_{\mathrm{E}, \mathrm{W}}$ are the wet delay gradient components in the northern and eastern directions. The last term $R$ refers to the post-fit residuals.

\subsection{WVR observations}

One water vapor radiometer (WVR), which is located at the Hong Kong Observatory (HKO) (shown in Fig. 1), is used for this study. This WVR uses seven oxygen channels and five water vapor channels to make observations of the temperature, humidity and liquid water vapor profiles up to $10 \mathrm{~km}$ above the ground in the zenith mode (Chan, 2010). The HKO employs a neural network approach and radiosonde profiles to establish a statistical model between the WVR brightness temperature and the vertical profiles of temperature and relative humidity (Chan, 2010). Based on this statistical model, temperature and relative humidity profiles can be retrieved from the WVR's brightness temperature measurements. The WVR data used in this study have a temporal resolution of 15 min.

\subsection{Water vapor data derived from the NWP}

The NWP non-hydrostatic model provides a good means to investigate small-scale meteorological phenomena (Saito, 2007). On 1 September 2004, the Japan Meteorological Agency (JMA) started to run a non-hydrostatic model with a horizontal resolution of $10 \mathrm{~km}$ to support weather disaster prevention (Saito et al., 2006). Based on the successful trials of using the JMA non-hydrostatic model, HKO has been operating a new NWP system since 2010 (Chan et al., 2010). This system has the ability to perform predictions at a horizontal resolution of $2 \mathrm{~km}$ and a temporal solution of $1 \mathrm{~h}$ (Wong, 2010). The domain of this model is $608 \mathrm{~km} \times 608 \mathrm{~km}$, which covers Hong Kong and its surrounding regions. It can output several parameters such as temperature, dew point depression and geopotential height at 16 isobaric levels ranging from 1000 to $100 \mathrm{hPa}$ at the top level. However, NWP data have a limited precision because they are predicted based on physical principles rather than real observations.

In tomographic modeling, a considerable amount of SWD data that do not fully traverse the tomographic volume are not used (see the dashed rays that cross the gray shaded area in Fig. 2). However, these SWD data (especially at low elevations) are helpful to improve the lower layers' reconstruction (Notarpietro et al., 2011). In order to make a full use of the SWDs, the SWDs that partially pass through the tomographic modeling area are divided into two parts. As shown in Fig. 2, the SWD inside the tomography volume is called $\mathrm{SWD}_{\mathrm{in}}$, and the rest that is outside the modeling area is referred to as $\mathrm{SWD}_{\text {out }}$. The $\mathrm{SWD}_{\text {out }}$ cannot be used for the tomographic modeling since it is outside of the modeling region. In this study, the $\mathrm{SWD}_{\text {out }}$ is calculated from the NWP profile data. After subtracting the $\mathrm{SWD}_{\text {out }}$ from the SWD, the $\mathrm{SWD}_{\text {in }}$ can be derived, and will be used in the tomographic modeling process.

\subsection{AERONET observations}

AERONET is a ground-based network consisting of more than 300 globally distributed sun photometers that are mainly used to study atmospheric aerosol properties (Holben et al., 1998; Liu et al., 2013b). The sun photometers are able to make direct solar extinction measurements at multiple wavelengths ranging from 340 to $1640 \mathrm{~nm}$ with an interval of $15 \mathrm{~min}$ (Giles et al., 2012; Holben et al., 2001). The observations made at the wavelength of $940 \mathrm{~nm}$ can be employed to retrieve water vapor (Holben et al., 2001). At present, 
there are two AERONET sun photometers operating in Hong Kong (as seen in Fig. 1). Liu et al. (2013a) did an assessment of 6 years of water vapor measurements recorded by the AERONET station in Hong Kong. Their study demonstrated that the AERONET sun photometer can provide accurate precipitable water vapor measurements, and that the agreement with radiosonde water vapor data was $2.89 \mathrm{~mm}$ in RMSE. Thus, AERONET can be a good data source for water vapor tomography. One drawback of the sun photometer is that it can only work in periods with direct sunlight. No data are available from the nighttime or in conditions of precipitation.

\subsection{Vertical a priori information from radiosonde profiles}

With sensors ascending together with weather balloons, radiosondes can make meteorological observations including pressure, temperature and relative humidity at various heights (World Meteorological Organization, 2008). This enables us to get accurate wet refractivity profiles from radiosonde observations. In Hong Kong, there is one radiosonde station located at the King's Park $\left(22.31^{\circ} \mathrm{N}\right.$, $114.17^{\circ} \mathrm{E}$ ) and this station is operated by the HKO. A radiosonde balloon is launched twice daily at 00:00 and 12:00 UTC, respectively. Water vapor profiles retrieved from radiosondes are often adopted as vertical a priori information in water vapor tomography (Bi et al., 2006; Champollion et al., 2009; Skone and Hoyle, 2005). Good a priori water vapor information can significantly improve tomographic results, especially for flat regions (Notarpietro et al., 2011). Hong Kong is a relatively flat region. The largest altitude difference among the 12 GNSS stations is only about $330 \mathrm{~m}$. It is therefore very crucial to impose good a priori vertical information for water vapor tomographic modeling in the Hong Kong region. HKO has archived a long time series of water vapor profile records. By statistical analysis of the Hong Kong radiosonde profiles over the 10 years (2003-2012), a priori information of wet refractivity vertical distribution in Hong Kong is derived. In this tomographic study, we are going to evaluate the impact of five schemes of different a priori vertical information on the tomographic modeling solutions. The details of the five schemes are described as follows.

V1. In our tomography model, the troposphere is divided into 15 nonuniform layers (more details in Sect. 3). The water vapor profile for each vertical layer is averaged from 3-day radiosonde observations prior to the tomographic modeling.

V2. For each vertical layer, the a priori wet refractivity value is averaged from 10 years (2003-2012) of radiosonde data. Meanwhile, a statistical variance-covariance matrix for the a priori information is generated from the 10 -year radiosonde wet refractivity profiles, which will be used to determine the weight matrix for the vertical a priori information in the tomography.

V3. Similar to V2, statistics are performed with the 10 years of radiosonde data for every month. Therefore, one mean value and one statistical variance-covariance matrix can be derived for each month. In the tomography, a priori information corresponding to the tomographic modeling month is employed.

V4. Different from V1 to V3, ratios of wet refractivity between each two neighboring layers are used as a priori information. For each pair of neighboring vertical layers, the average ratio of their wet refractivities is derived from the 10 years of radiosonde profiles. A statistical variance-covariance matrix for the ratios can also be calculated.

V5. Similar to V4, statistics are performed with the 10 years of radiosonde data for every month. Therefore, for each month, a pair of average ratio value and statistical variance-covariance matrix is derived. The same as V3, a priori information corresponding to the tomographic modeling month is employed in the tomography.

\section{Water vapor tomography with multi-source data}

When GPS radio signals propagate through the troposphere, they are delayed due to the refraction of water vapor. The excess path experienced by the radio signals is often referred to as tropospheric wet delay, which can be expressed as

$\mathrm{SWD}=10^{-6} \int_{l} N_{\mathrm{w}} d_{l}$,

where $N_{\mathrm{w}}$ represents the wet refractivity, and $l$ is the ray path of the radio signal through the troposphere. The wet refractivity is a function of the partial pressure of water vapor $e$ (unit: $\mathrm{hPa}$ ) and the temperature $T$ (unit: Kelvin degree) (Rüeger, 2002; Smith and Weintraub, 1953):

$N_{\mathrm{w}}=22.9721 \frac{e}{T}+375463 \frac{e}{T^{2}}$.

The wet refractivity is an important parameter describing the water vapor distribution in the atmosphere. According to Eq. (3), the wet refractivity of a certain point can be obtained by measuring the ambient air pressure and temperature. However, it is difficult to acquire meteorological observations in the upper atmosphere. Developing a tomographic modeling approach to characterize water vapor 3-D spatial distribution is therefore highly desired.

In Fig. 3, the probed tropospheric region is divided into 8 voxels, with the assumption that the wet refractivity inside each voxel is invariable during the tomographic modeling period. Examining the R1-S2 ray path, it can be observed that 


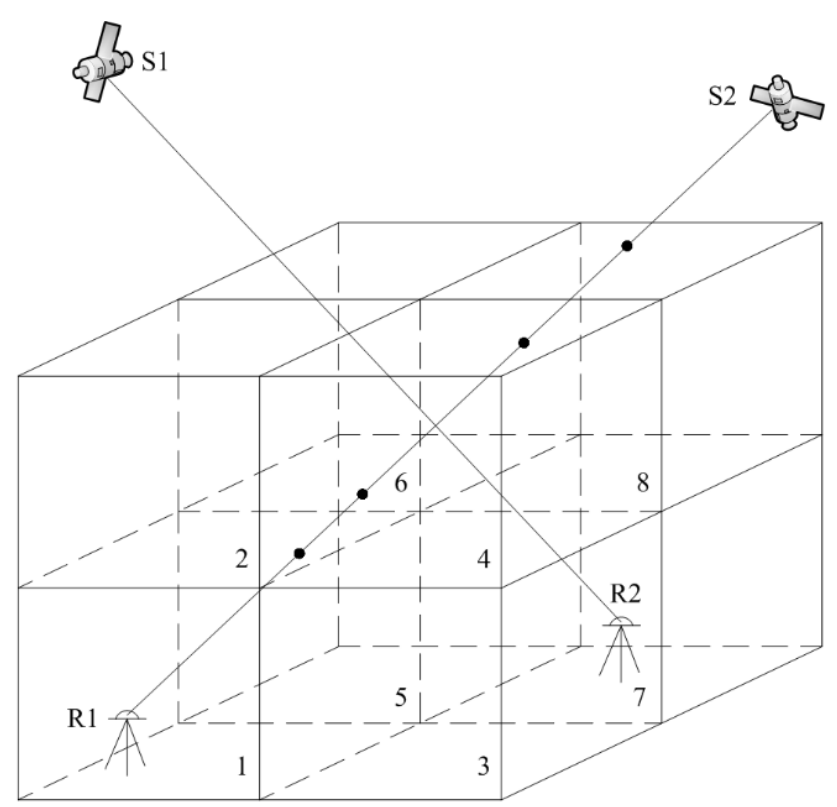

Figure 3. Schematic representation of 3-D water vapor tomography.

it passes through 4 voxels numbered as 1, 2, 4 and 8 . In the tomographic technique, the SWD should be equal to the summation of the product of wet refractivity and the length of ray path within each voxel. For the R1-S2 ray, we can thus get

$\mathrm{SWD}_{\mathrm{R} 1-\mathrm{S} 2}=a_{1} \cdot x_{1}+a_{2} \cdot x_{2}+a_{4} \cdot x_{4}+a_{8} \cdot x_{8}$,

where $a_{i}(i=1,2,4,8)$ represents the length of ray intercepted by voxel $i$, and $x_{i}$ stands for the wet refractivity in voxel $i$. Actually, Eq. (4) is the linear form of Eq. (2). During a tomographic process, a lot of ray paths linking GPS satellites and ground GPS receivers will traverse the 3-D modeling voxels. Thus, Eq. (4) can be rewritten in the matrix form

$\boldsymbol{y}=\mathbf{A} \cdot \boldsymbol{x}$,

where $\boldsymbol{y}$ is the vector of water vapor observations, e.g., the slant wet delays derived from GPS observations; $\boldsymbol{x}$ is the vector of unknown wet refractivity of each voxel; A represents the matrix describing the path length of each signal intercepted by each voxel. It should be noted that the wet refractivity field can hardly be inverted by Eq. (5), as not all voxels are crossed by GPS satellite signals. To overcome the rank-defect problem, extra water vapor observations and constraints are needed. As described in Sect. 2, WVR, NWP, AERONET and synoptic stations can also provide water vapor measurements. In addition, the vertical a priori information derived from radiosonde profiles and horizontal smoothing constraint are augmented to Eq. (5) to increase the rank of matrix A. The horizontal constraint is added based on the assumption that wet refractivity in a voxel is the weighted average of its horizontal neighbors (Flores et al., 2000). Combining all available observations and constraints, the tomog- raphy Eq. (5) becomes

$$
\left(\begin{array}{l}
\boldsymbol{y}_{\mathrm{G}} \\
\boldsymbol{y}_{\mathrm{w}} \\
\boldsymbol{y}_{\mathrm{N}} \\
\boldsymbol{y}_{\mathrm{A}} \\
\boldsymbol{y}_{\mathrm{s}} \\
\boldsymbol{y}_{\mathrm{R}} \\
0
\end{array}\right)=\left(\begin{array}{c}
\mathbf{A}_{\mathrm{G}} \\
\mathbf{A}_{\mathrm{w}} \\
\mathbf{A}_{\mathrm{N}} \\
\mathbf{A}_{\mathrm{A}} \\
\mathbf{A}_{\mathrm{s}} \\
\mathbf{A}_{\mathrm{R}} \\
\mathbf{H}
\end{array}\right) \cdot \boldsymbol{x},
$$

where $\boldsymbol{y}_{\mathrm{G}}, \boldsymbol{y}_{\mathrm{W}}, \boldsymbol{y}_{\mathrm{N}}, \boldsymbol{y}_{\mathrm{A}}, \boldsymbol{y}_{\mathrm{s}}$ and $\boldsymbol{y}_{\mathrm{R}}$ refer to the water vapor data derived from GPS, WVR, NWP, AERONET, synoptic observations and radiosonde measurements, respectively; A with subscripts represents coefficient matrix for each type of data; $\mathbf{H}$ is the coefficient matrix for the horizontal constraint. By performing the least squares method, the wet refractivity of all the voxels can be solved as follows:

$$
\begin{aligned}
\boldsymbol{x}= & {\left[w _ { 1 } \cdot \left(\mathbf{A}_{\mathrm{G}}^{\mathrm{T}} \cdot \mathbf{P}_{\mathrm{G}} \cdot \mathbf{A}_{\mathrm{G}}+\mathbf{A}_{\mathrm{W}}^{\mathrm{T}} \cdot \mathbf{P}_{\mathrm{W}} \cdot \mathbf{A}_{\mathrm{W}}+\mathbf{A}_{\mathrm{A}}^{\mathrm{T}} \cdot \mathbf{P}_{\mathrm{A}}\right.\right.} \\
& \left.\cdot \mathbf{A}_{\mathrm{A}}+\mathbf{A}_{\mathrm{s}}^{\mathrm{T}} \cdot \mathbf{P}_{\mathrm{s}} \cdot \mathbf{A}_{\mathrm{s}}+\mathbf{A}_{\mathrm{R}}^{\mathrm{T}} \cdot \mathbf{P}_{\mathrm{R}} \cdot \mathbf{A}_{\mathrm{R}}\right)+w_{2} \cdot \mathbf{A}_{\mathrm{N}}^{\mathrm{T}} \\
& \left.\cdot \mathbf{P}_{\mathrm{N}} \cdot \mathbf{A}_{\mathrm{N}}+w_{3} \cdot \mathbf{H}^{\mathrm{T}} \cdot \mathbf{P}_{\mathrm{H}} \cdot \mathbf{H}\right]^{-1} \cdot\left[w _ { 1 } \cdot \left(\mathbf{A}_{\mathrm{G}}^{\mathrm{T}} \cdot \mathbf{P}_{\mathrm{G}}\right.\right. \\
& \cdot \boldsymbol{y}_{\mathrm{G}}+\mathbf{A}_{\mathrm{W}}^{\mathrm{T}} \cdot \mathbf{P}_{\mathrm{W}} \cdot \boldsymbol{y}_{\mathrm{W}}+\mathbf{A}_{\mathrm{A}}^{\mathrm{T}} \cdot \mathbf{P}_{\mathrm{A}} \cdot \boldsymbol{y}_{\mathrm{A}}+\mathbf{A}_{\mathrm{s}}^{\mathrm{T}} \cdot \mathbf{P}_{\mathrm{s}} \\
& \left.\left.\cdot \boldsymbol{y}_{\mathrm{s}}+\mathbf{A}_{\mathrm{R}}^{\mathrm{T}} \cdot \mathbf{P}_{\mathrm{R}} \cdot \boldsymbol{y}_{\mathrm{R}}\right)+w_{2} \cdot \mathbf{A}_{\mathrm{N}}^{\mathrm{T}} \cdot \mathbf{P}_{\mathrm{N}} \cdot \boldsymbol{y}_{\mathrm{N}}\right]
\end{aligned}
$$

where $w_{1}, w_{2}$ and $w_{3}$ are weighting factors that will be discussed later; $\mathbf{P}$ with subscripts represents weight matrix for each type of data and constraints. In general, the weight matrix should be determined from the variance-covariance matrix that is derived from the analysis of the accuracy of observations. For most of the observations, however, this information is currently not available. Therefore, the observation weights are determined as follows. Both $\mathbf{P}_{\mathrm{G}}$ and $\mathbf{P}_{\mathrm{N}}$ weight matrices are diagonal with elements defined as $\sin (\theta)$ ( $\theta$ refers to the elevation angle of the SWD of a given GPS satellite). This is based on the fact that the error in SWD usually increases when the elevation angle decreases. For the weight matrices $\mathbf{P}_{\mathrm{W}}, \mathbf{P}_{\mathrm{A}}, \mathbf{P}_{\mathrm{s}}$ and $\mathbf{P}_{\mathrm{H}}$, they are defined as unit matrices since variance-covariance matrices of these data are currently not available and also hard to be obtained. As mentioned in Sect. 2.5, the weight matrix $\mathbf{P}_{\mathrm{R}}$ is from the statistical variance-covariance matrix that derived from the radiosonde profiles. The three weighting factors $w_{1}, w_{2}$ and $w_{3}$ in Eq. (7) are determined by using the Helmert variance component estimation method (Kizilsu and Sahin, 2000; Wang et al., 2009). The reasons for categorizing the GPS, WVR, AERONET, synoptic observations and radiosonde data into one group are as follows: (1) water vapor measurements from these techniques are at a similar level. In our previous comparisons with radiosondes over a half-year period from May to October 2013, GPS, WVR and AERONET data achieve accuracies of $18.06,18.15$ and $17.95 \mathrm{~mm}$, respectively. Their accuracies are very similar; (2) the number of observations from WVR, AERONET and synoptic stations 
Table 1. Statistics of the differences between GPS-inferred SWD/ZWD and tomography-derived SWD/ZWD over the HKLT station (unit: $\mathrm{mm})$.

\begin{tabular}{lrr|rr|rr|r|rr}
\hline & \multicolumn{4}{c}{ Tomo-I } & \multicolumn{4}{c}{ Tomo-II } \\
\cline { 2 - 9 } Vertical & \multicolumn{2}{c}{ SWD } & \multicolumn{2}{c|}{ ZWD } & \multicolumn{2}{c}{ SWD } & \multicolumn{2}{c}{ ZWD } \\
\cline { 2 - 9 } constraint & Bias & RMSE & Bias & RMSE & Bias & RMSE & Bias & RMSE \\
\hline V1 & -1.58 & 11.30 & 0.17 & 7.07 & -0.57 & 10.85 & -0.71 & 6.46 \\
V2 & 3.80 & 12.85 & -0.85 & 7.76 & 4.16 & 12.29 & -1.58 & 7.54 \\
V3 & 3.44 & 12.61 & -0.74 & 7.38 & 3.00 & 11.47 & -1.15 & 7.18 \\
V4 & 3.60 & 12.05 & -0.87 & 7.36 & 4.05 & 11.97 & -1.63 & 7.31 \\
V5 & 3.19 & 11.59 & -0.85 & 7.17 & 3.88 & 11.75 & -1.55 & 7.21 \\
\hline
\end{tabular}

is much smaller compared with GPS data. Since the NWP data have lower accuracy than GPS data, and a tight horizontal constraint can result in a very smooth water vapor distribution in the horizontal direction, two weighting factors are assigned to adjust their impact on the result. Actually, our tomographic experiments show that $w_{2}$ and $w_{3}$ are always smaller than $w_{1}$, which implies that the impact of NWP data and horizontal constraint to the solution is degraded. Since the wet refractivity field obtained from Eq. (7) is just an approximate solution, the multiplicative algebraic reconstruction technique (MART) is finally implemented to improve the wet refractivity solution from Eq. (7) (Bender et al., 2011; Chen and Liu, 2014). The least squares solution of Eq. (7) provides an initial state to the MART algorithm to converge, which will produce a more accurate wet refractivity filed. The advantages of this combined reconstruction algorithm have been demonstrated in several studies (Notarpietro et al., 2011; Wen et al., 2008; Xia et al., 2013). In this study, tomographic model is discretized using the method developed in Chen and Liu (2014). In the horizontal, resolutions of $0.08^{\circ}$ (about $8.5 \mathrm{~km}$ ) are set for both latitude and longitude directions. The top boundary of $8.5 \mathrm{~km}$ is adopted for the tomography model (Liu et al., 2014). From the surface to the top, the troposphere is divided into 15 nonuniform layers in the vertical direction (Chen and Liu, 2014). From the ground upward, the layer thickness is arranged as follows: $400 \mathrm{~m}$ for the bottom five layers, $500 \mathrm{~m}$ for the next four layers, $600 \mathrm{~m}$ for the next three layers, $700 \mathrm{~m}$ for one layer and $1000 \mathrm{~m}$ for the top two layers.

\section{Analysis of the tomographic results}

Many tests have been carried out to evaluate the performance of the above water vapor tomographic model. The multisource data used in the tests were collected from May to October 2013, the most humid period in a year in Hong Kong. Severe weathers such as typhoons and rainstorms often occur in these months. Assessing the model's performance of retrieving spatial distribution and temporal variation of atmospheric water vapor under severe weather conditions is particularly interesting to us because 3-D water vapor distribution and propagation information can provide valuable assistance to weather forecasters. In this study, tomography is performed consecutively with an interval of $30 \mathrm{~min}$. In order to identify the best vertical a priori information, the five different schemes as described in Sect. 2.5 are used. SWD data from the GPS observations of HKLT station are used for quality assessment, and thus are not used in the tomographic modeling. In addition, radiosonde profiles are also exploited to assess the tomographic vertical distribution of wet refractivity.

\subsection{Water vapor tomographic performance using multi-source data}

Once we obtain the tomographic wet refractivity field from Eq. (7), SWD along a specific ray path can be derived by an integral of the GPS path length and water vapor refractivity in each voxel. These tomographic SWDs can be directly compared with those SWDs retrieved from GPS observations. To evaluate the performance enhancement of using multi-source water vapor data in tomography, we carry out a tomography using GPS water vapor data. For brevity, this tomography is named as Tomo-I, and the tomography using multi-source water vapor data is referred to as Tomo-II in this paper. For both Tomo-I and Tomo-II, the five vertical a priori information schemes are implemented, and the corresponding results of tomographic wet refractivity field are evaluated.

Table 1 shows the self-consistency results obtained from different vertical a priori information schemes. The statistics are calculated from the differences between GPS-inferred SWD/ZWD and tomography-derived SWD/ZWD over the HKLT station (the evaluation GPS station). It can be seen that vertical constraint scheme V1 achieves the best performance in both Tomo-I and Tomo-II with RMSEs of 11.30 and $10.85 \mathrm{~mm}$ for the slant wet delay (SWD), respectively. In addition, vertical constraint V3 performs better than V2, likewise for V5 and V4. This can be easily explained as follows: vertical constraint schemes V3 and V5 consider the variations of water vapor in different months, but the vertical a priori information is invariable in both V2 and V4. 

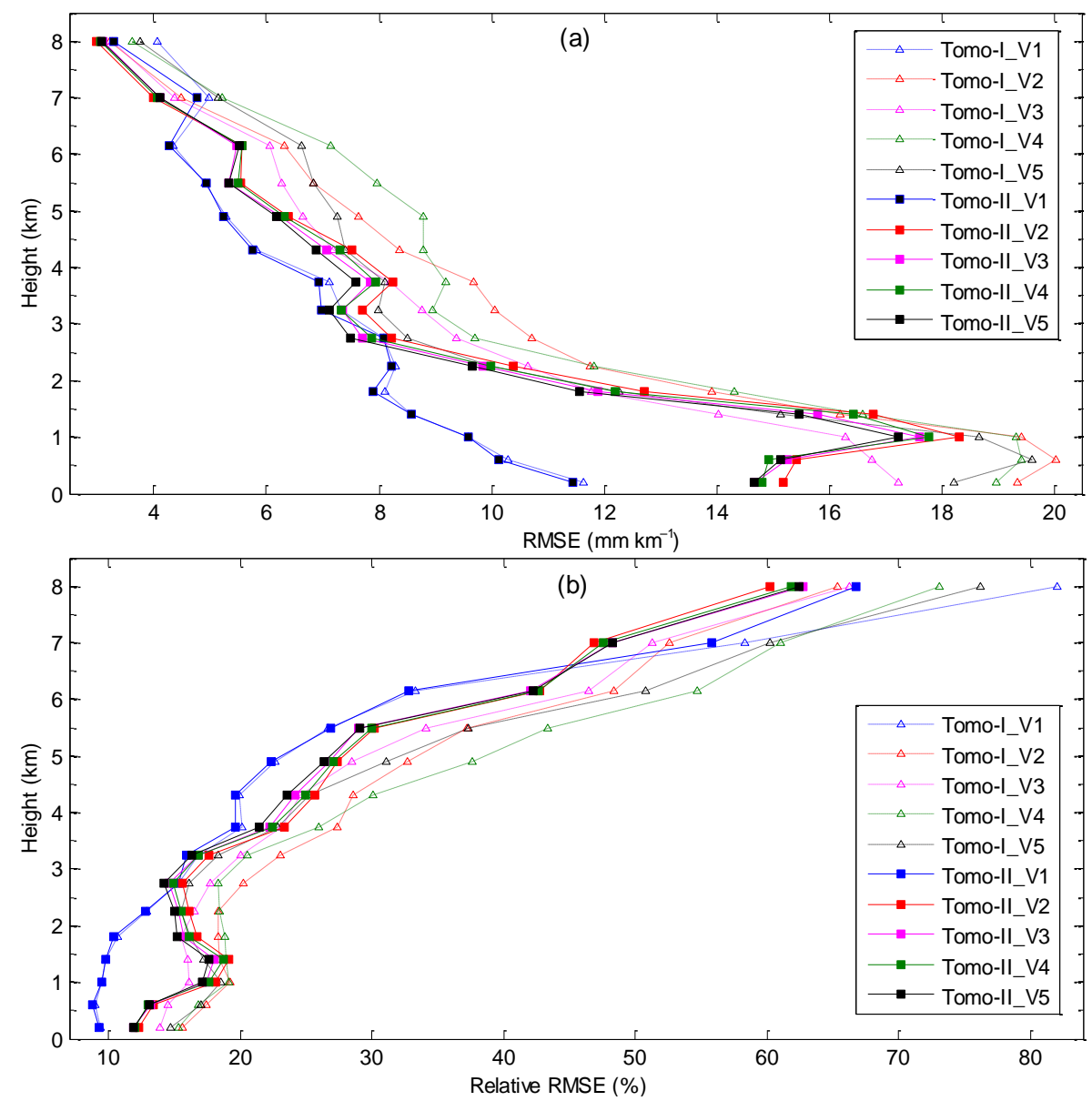

Figure 4. RMSEs (a) and relative RMSEs (b) of the differences between wet refractivity derived from radiosonde and tomography on different altitude layers during May to October 2013.

Comparing the performance of Tomo-I with Tomo-II, we can observe that tomographic results from Tomo-II have higher accuracy than those from Tomo-I, except for the scheme V5. The Tomo-II with scheme V1 achieves the highest RMSE accuracy of $6.46 \mathrm{~mm}$ in ZWD.

The tomographic results are also assessed using radiosonde vertical profile data. Statistical results of the differences of wet refractivity between radiosonde and tomography are presented in Table 2. The comparison results further demonstrate that V1 is the best vertical constraint scheme. As seen in Table 2, vertical constraint scheme V1 achieves an accuracy of $7.26 \mathrm{~mm} \mathrm{~km}^{-1}$ in Tomo-I and an even higher accuracy with an RMSE of $7.13 \mathrm{~mm} \mathrm{~km}^{-1}$ in Tomo-II. For the other four schemes, their RMSEs range from 9.42 to $11.44 \mathrm{~mm} \mathrm{~km}^{-1}$, clearly greater than the scheme V1. The tomographic results solved from schemes V 3 and V5 are better than schemes V2 and V4, respectively. This is also consistent with the evaluation shown in Table 1 using GPS data. In Table 2, it is worth mentioning that for all five schemes, tomographic results from Tomo-II are all consistently better than those of Tomo-I. Considering the results in both Tables 1 and 2, we can conclude that scheme V1 is the best vertical constraint scheme. This reveals that averaging radiosonde profiles over a 3-day period as water vapor vertical a priori information is better than averaging them over a longer period; that is to say, it is better to employ recently observed radiosonde profiles as vertical a priori information in the tomography. In addition, it is demonstrated that the assimilation of multi-source data into the water vapor tomography (Tomo-II) can improve the tomographic reconstruction accuracy over the tomography using GPS water vapor data only (Tomo-I).

The comparison analysis presented above shows the overall accuracy along a slant or zenith path but does not show the accuracy of tomographic results at different layers. To study the tomographic accuracy at different altitudes, the RMSEs and the relative RMSEs of the differences between radiosonde and tomography at different layers are calculated. The relative RMSE is defined as the radiosonde-measured wet refractivity divided by the RMSE. Figure 4 shows the change of RMSE and relative RMSE with altitude for 10 different scenarios defined in Table 1. Generally, the RMSE 


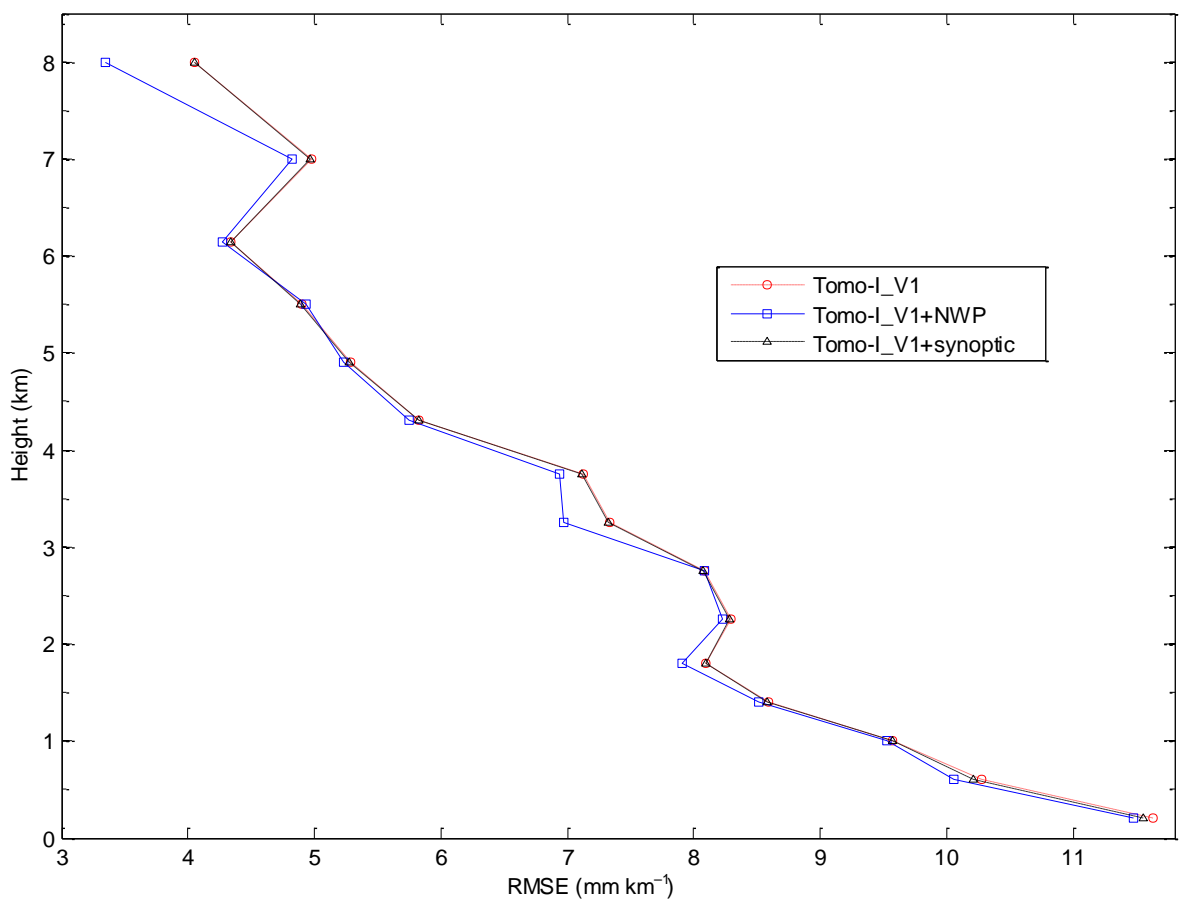

Figure 5. RMSEs of the differences between wet refractivity derived from radiosonde and tomography on different altitude layers. Based on the scheme Tomo-I_V1, tomography is performed with additional data from NWP (Tomo-I_V1 + NWP) and synoptic stations (TomoI_V1 + synoptic), respectively.

Table 2. Statistics of the differences of wet refractivity between radiosonde measurements and tomography (unit: $\mathrm{mm} \mathrm{km}^{-1}$ ).

\begin{tabular}{|c|c|c|c|c|}
\hline \multirow[t]{2}{*}{$\begin{array}{l}\text { Vertical } \\
\text { constraint }\end{array}$} & \multicolumn{2}{|c|}{ Tomo-I } & \multicolumn{2}{|c|}{ Tomo-II } \\
\hline & Bias & RMSE & Bias & RMSE \\
\hline V1 & 0.71 & 7.26 & 0.85 & 7.13 \\
\hline $\mathrm{V} 2$ & 1.00 & 11.29 & 1.31 & 10.01 \\
\hline V3 & 1.22 & 9.85 & 1.37 & 9.64 \\
\hline V4 & 0.96 & 11.44 & 1.36 & 9.73 \\
\hline V5 & 1.39 & 10.53 & 1.36 & 9.42 \\
\hline
\end{tabular}

decreases with an increase in altitude due to the water vapor content decreasing with altitude. For the best scenario Tomo-II_V1, its RMSE is $11.44 \mathrm{~mm} \mathrm{~km}^{-1}$ at the lowest layer $(0-0.4 \mathrm{~km})$, and it decreases to $3.30 \mathrm{~mm} \mathrm{~km}^{-1}$ at the uppermost layer $(7.5-8.5 \mathrm{~km})$. In terms of the relative RMSE, its value increases from $9 \%$ at the lowest layer to $67 \%$ at the uppermost layer for Tomo-II_V1, revealing the deficiency of tomography in retrieving the water vapor of high-altitude layers. Generally speaking, tomographic wet refractivity fields solved by Tomo-II (curve with solid square) are better than those derived by Tomo-I (dashed line with hollow triangle) at most of the layers. For the scheme V1, Tomo-II shows slightly better performance than Tomo-I at all layers. Referring to the other four schemes, it can be seen from Fig. 4 that tomographic results solved from Tomo-II are significantly better than those from Tomo-I, especially in the lower layers. This clearly demonstrates the positive contribution of multisource water vapor data to the water vapor tomography. As indicated before, the four schemes V2 to V5 are probably too coarse to characterize the vertical variation of the water vapor. Especially in a flat region like Hong Kong, the accuracy of tomography is highly dependent on the accuracy of vertical a priori information. In addition, the tomography scheme Tomo-I_V1 is performed with additional data from NWP (Tomo-I_V1 + NWP) and the synoptic station (TomoI_V1 + synoptic) to test their respective impacts on the tomographic solutions. As seen in Fig. 5, the assimilation of NWP improves the tomographic solutions at various layers. For the assimilation of surface humidity data from synoptic stations, it slightly increases the tomographic accuracy at the lowest two layers, while no obvious differences can be observed at other layers. It is expected that the assimilation of surface humidity data from more weather stations can further improve the tomographic solutions of lower layers.

\subsection{Capability of the tomography under conditions of heavy precipitation}

The overall performance of the water vapor tomography using multi-source data is evaluated in the last section. It should be noted that one of very important goals of water vapor tomography is to provide accurate 3-D water vapor data and 

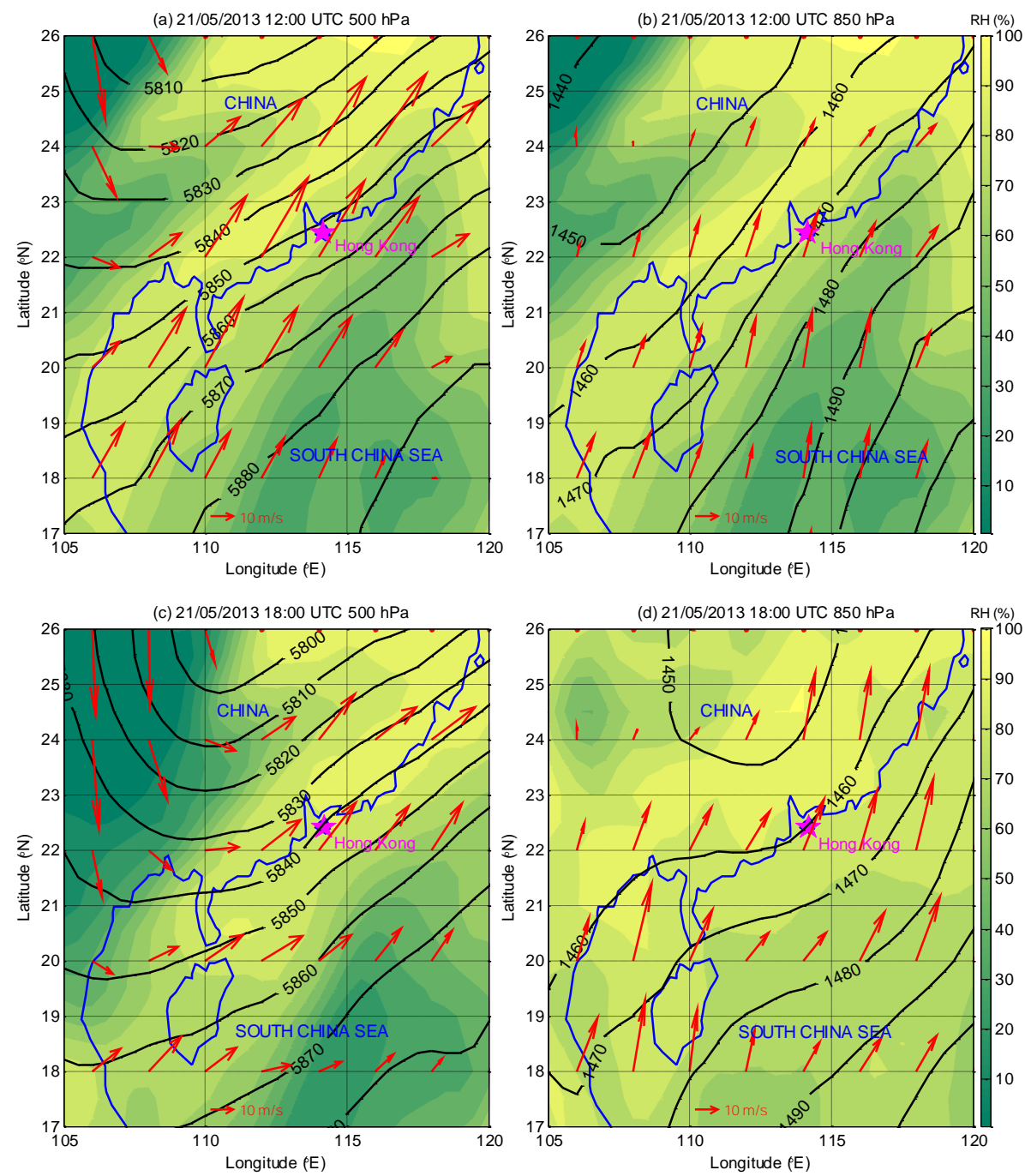

Figure 6. Isobaric analysis at (a) $500 \mathrm{hPa}$ and (b) $850 \mathrm{hPa}$ at 12:00, and (c) $500 \mathrm{hPa}$ and (d) $850 \mathrm{hPa}$ at 18:00 over southern China on 21 May 2013. The black contours represent the geopotential heights. The filled contours are relative humidities. Red arrows indicate the wind direction, and the vector scale is shown at the bottom in the middle. The meteorological data are derived from the ECMWF ERA-Interim reanalysis products.

information to support weather forecasting under heavy precipitation conditions. The heavy precipitation is defined as accumulated rainfall exceeding $30 \mathrm{~mm}$ within $1 \mathrm{~h}$. During the study period May to October 2013, heavy precipitation events occurred on a total of 15 days. This section will focus on tomographic accuracy assessment under heavy precipitation conditions. The last section demonstrates that the scheme Tomo-II_V1 can achieve the highest tomographic accuracy; thus only this scheme is used in the performance assessment in this section.

As seen in Table 3, the RMSE of the differences between tomographic SWD and GPS-inferred SWD is $10.98 \mathrm{~mm}$ under conditions of heavy precipitation. For the comparison between tomography and radiosonde, an RMSE of $7.36 \mathrm{~mm} \mathrm{~km}^{-1}$ is yielded. It can be noted that their RMSEs
Table 3. Comparison of tomography with GPS and radiosonde measurements under conditions of heavy precipitation during May to October 2013. Tomography is carried out using multi-source data with the vertical constraint scheme V1.

\begin{tabular}{lc|cc}
\hline $\begin{array}{c}\text { Tomography vs. GPS } \\
(\mathrm{mm})\end{array}$ & \multicolumn{2}{|c}{$\begin{array}{c}\text { Tomography vs. radiosonde } \\
\left(\mathrm{mm} \mathrm{km}^{-1}\right)\end{array}$} \\
\hline Bias & RMSE & Bias & RMSE \\
\hline 2.25 & 10.98 & 1.17 & 7.36 \\
\hline
\end{tabular}

are slightly larger than the overall RMSEs shown in the previous sections. This is due to the fact that water vapor is much more dynamic and abundant under heavy precipitation con- 
ditions. Nevertheless, the tomography still achieves a good accuracy during heavy precipitation conditions. This demonstrates that the robustness of this water vapor tomographic modeling software system and that only slight degradation in water vapor tomographic accuracy can be observed under heavy precipitation conditions.

During 21-22 May 2013, a torrential storm occurred in Hong Kong with daily rainfall of $190 \mathrm{~mm}$, which was the maximum daily rainfall over the past 5 years. On that day, HKO issued the highest level of warning signal - black rainstorm (black rainstorm signal means heavy rain exceeding $70 \mathrm{~mm}$ in $1 \mathrm{~h}$ ). The rainstorm lasted about $9 \mathrm{~h}$ from 21 May 17:00 UT to 22 May 2013 02:00 UT. Figure 6 presents the meteorological synopsis derived from the ECMWF (European Centre for Medium-Range Weather Forecasts) ERAInterim reanalysis over southern China at 12:00 and 18:00 on 21 May at two pressure levels: 500 and $850 \mathrm{hPa}$. The air over Hong Kong and surrounding regions was observed to be very humid. Relative humidity around Hong Kong increased at both pressure levels within the $6 \mathrm{~h}$ from 12:00 to 18:00. The wind field information showed that strong southwesterly winds occurred over Hong Kong, which brought water vapor from the southwest to Hong Kong.

The water vapor tomographic technique provides us with a powerful tool to investigate the spatiotemporal characteristics of the water vapor variability for this severe convective weather. By using the tomographic wet refractivity and pressure and temperature data provided by the NWP model, the partial pressure of water vapor can be solved from Eq. (3), and the relative humidity field could be further determined. Figure 7a presents the evolution of tomographic relative humidity profiles at the $\mathrm{HKO}$ weather station $\left(22.30^{\circ} \mathrm{N}\right.$, $114.17^{\circ} \mathrm{E}$ ) during the period from 21 May 04:00 UT to 22 May 2013 10:00 UT. The evolution of ZWDs derived from tomography (30 min time resolution), NWP ( $1 \mathrm{~h}$ time resolution) and radiosondes ( $12 \mathrm{~h}$ time resolution) is shown in Fig. $7 \mathrm{~b}$ along the same time series. Tomography has good agreement with radiosonde measurements, whereas large differences exist between tomography and NWP. This demonstrates the relatively poor performance of NWP in describing the atmospheric water vapor. Examining the tomographyderived total $Z W D$, it can be observed that total ZWD values continuously increased from $\sim 340 \mathrm{~mm}$ at 21 May 07:00 UT to $\sim 400 \mathrm{~mm}$ at 21 May 17:30 UT when the precipitation started. After that the total ZWD shows a small decrease followed by a quick increase. When the total ZWD peaked at 21 May 19:30 UT, the torrential rain came. Because of the rain downpour, the total ZWD decreased quickly. In the $5 \mathrm{~h}$ following 21 May 21:00 UT, the total ZWD fluctuated, while the heavy rain weakened to drizzles. It can also be seen that the total ZWD shows a quick decrease after the end of this precipitation event. Examining the tomographic relative humidity profiles in Fig. 7a can help us to better understand the spatiotemporal variation of the water vapor during the rainstorm. We can find that the change of ZWD is mainly attributed to the variation of water vapor at lower layers. Especially the water vapor below $3 \mathrm{~km}$ showed evident fluctuations. During the rainstorm, relative humidities for layers below 2 and $3-5 \mathrm{~km}$ were very high, approaching $100 \%$, indicating that there was abundant water vapor to fuel the heavy rain. In addition, the ZWD variations at five layers are also given in Fig. 7c. The ZWD below $1 \mathrm{~km}$ reached a maximum on 21 May 2013 at 18:00, when the rain had just begun. Then, the ZWD below $1 \mathrm{~km}$ decreased quickly during the heavy precipitation. ZWDs between 1 and $2 \mathrm{~km}$ remained with a steady status and did not show much fluctuation. We can observe that the increase of the total ZWD during 21 May 2013, 18:00-20:00, is mainly attributed to the layers between 2 and $5 \mathrm{~km}$. At the same time, water vapor above $5 \mathrm{~km}$ showed a slow decrease followed by a sudden increase. In the $5 \mathrm{~h}$ subsequent to the heavy precipitation (21 May 21:00 UT to 22 May 02:00 UT), light rain continued. Water vapor in each layer still showed much fluctuation during this period. This indicated that the atmosphere was in an unstable condition, and precipitation continued to occur. Once the precipitation ended, it could be found that water vapor in different layers was gradually restored towards a steady state.

A more detailed illustration of the evolution of tomographic relative humidity profiles can be found in Fig. 8. Subgraphs tagged with "a" and "b" refer to the relative humidity sections along the longitude of $114.17^{\circ} \mathrm{E}$ (south-north section) and latitude of $22.30^{\circ} \mathrm{N}$ (west-east section), respectively. In Fig. 8 (panels 1a, b, 2a, b, 3a, b, 8a and b) the relative humidity profiles show relatively steady conditions. In Fig. 8 (panels 4a, b, 5a, b, 6a, b, 7a and b) we can observe there are some disturbances of relative humidity, implying the instability of the atmosphere. Especially in Fig. 8 (panels $5 \mathrm{a}$ and $\mathrm{b}$ ), large disturbances exist (relative humidities in most layers approach $100 \%$, and in some upper layers, values are close to 0 ), and we know that at this time, there was torrential rain. It should be noted that one of the prerequisites of forming a convective storm system is the existence of enough moisture in the lower troposphere to the mid-troposphere. The tomographic water vapor distribution shown in Figs. 7 and 8 indicates that there was abundant water vapor in the lower troposphere. This water vapor tomographic example during a typical rainstorm illustrates that the tomographic technique can reveal the spatial structure and temporal variation of the atmospheric water vapor under rainstorm conditions well.

\section{Discussion and conclusion}

As a crucially important atmospheric parameter, accurate water vapor data in the spatial and temporal domains can play a significant role in the study of many atmospheric processes. Water vapor tomography has been proven to be a powerful technique that is capable of retrieving the spatiotemporal distribution of the atmospheric water vapor. Traditionally, 


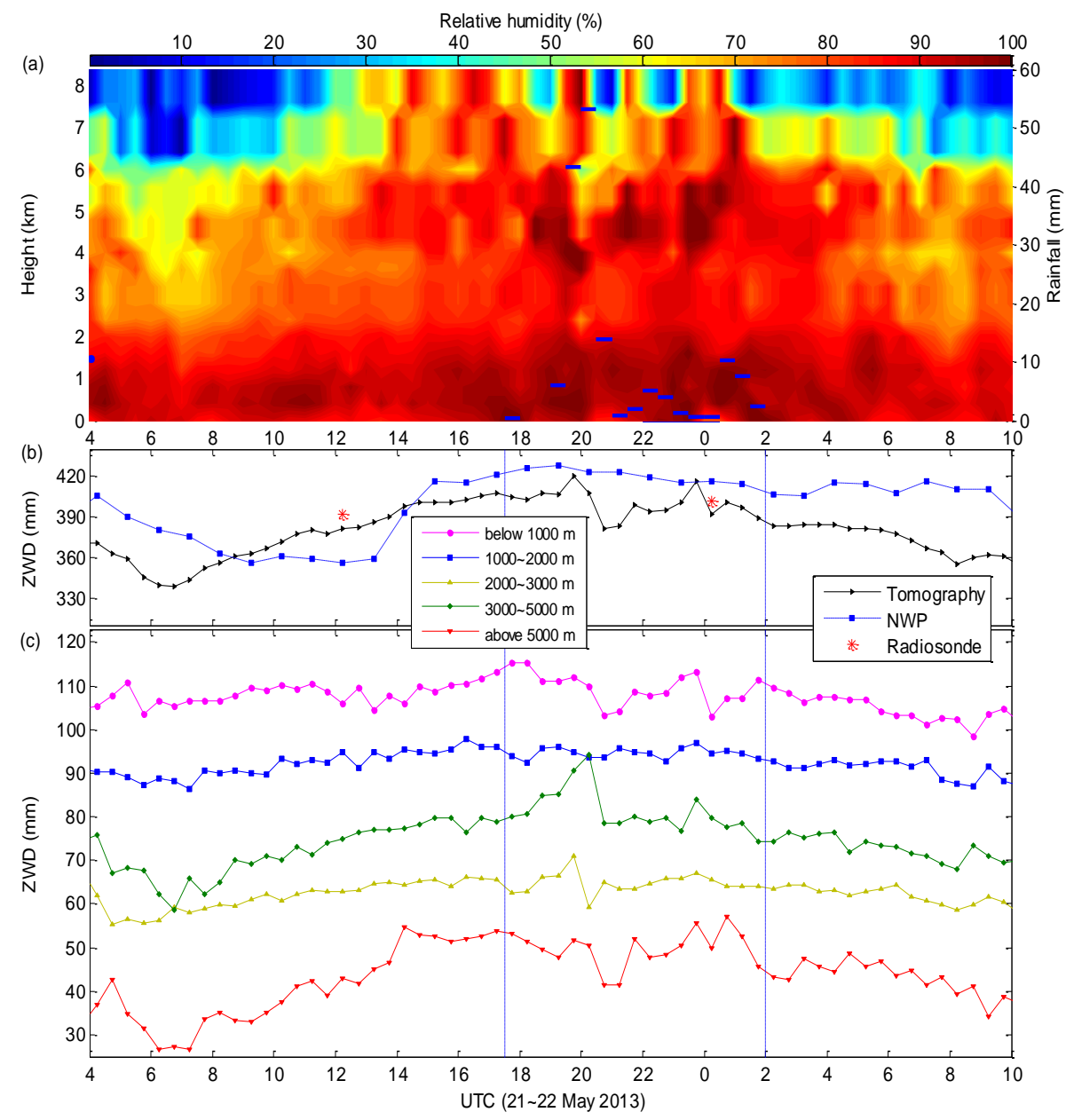

Figure 7. Evolution of tomographic relative humidity profiles (a), total ZWD (b) and ZWD at various layers (c) every 30 min from 21 May 04:00 UT to 22 May 2013 10:00 UT over the HKO weather station. The blue lines in panel (a) show the gauged rainfall within each 30 min, and their values correspond to the right vertical axis. Panel (c) presents the ZWD below the height of $1000 \mathrm{~m}$ (pink curve with circle), ZWD between 1000 and $2000 \mathrm{~m}$ (blue curve with square), ZWD between 2000 and $3000 \mathrm{~m}$ (yellow curve with triangle), ZWD between 3000 and $5000 \mathrm{~m}$ (green curve with rhomb) and ZWD above the height of $5000 \mathrm{~m}$ (red curve with inverse triangle).

water vapor tomography is often performed by using water vapor measurements derived from GPS/GNSS observations. The integration of GPS-derived and other sensors' water vapor data in principal can augment the tomographic modeling system and improve the water vapor modeling accuracy.

Based on this idea, this paper develops a multi-source water vapor tomographic modeling system in Hong Kong by using water vapor data collected from GPS, radiosonde, WVR, NWP, AERONET sun photometer and meteorological instruments' measurements. The radiosonde data are not directly employed. Instead, they are used to provide vertical a priori information for the tomography. Five different vertical constraint schemes are examined in this study. To show the performance, tomography results using multi-source data (Tomo-II) are compared against those using GPS water vapor data only (Tomo-I), using 6 months' data collected from May to October 2013.
Tomographic results are assessed with water vapor data derived from both GPS instruments and radiosondes. It shows that the scheme V1 of using vertical a priori information derived from 3 days of radiosonde observations prior to the tomographic epoch achieves the best performance in both Tomo-I and Tomo-II. With the use of the best vertical a priori information (scheme V1), the Tomo-II strategy has shown the following performance. (1) SWD data achieve an accuracy of $10.85 \mathrm{~mm}$ when assessed by GPSinferred SWD measurements. (2) The whole wet refractivity profiles yield an RMSE of $7.13 \mathrm{~mm} \mathrm{~km}^{-1}$ when assessed by radiosonde-observed wet refractivity data. (3) In terms of accuracy along the vertical layer, RMSEs generally decrease with altitude, from $11.44 \mathrm{~mm} \mathrm{~km}^{-1}$ at the lowest layer $(0-0.4 \mathrm{~km})$ to $3.30 \mathrm{~mm} \mathrm{~km}^{-1}$ at the uppermost layer $(7.5-$ $8.5 \mathrm{~km})$. The corresponding relative RMSEs increase from 9 


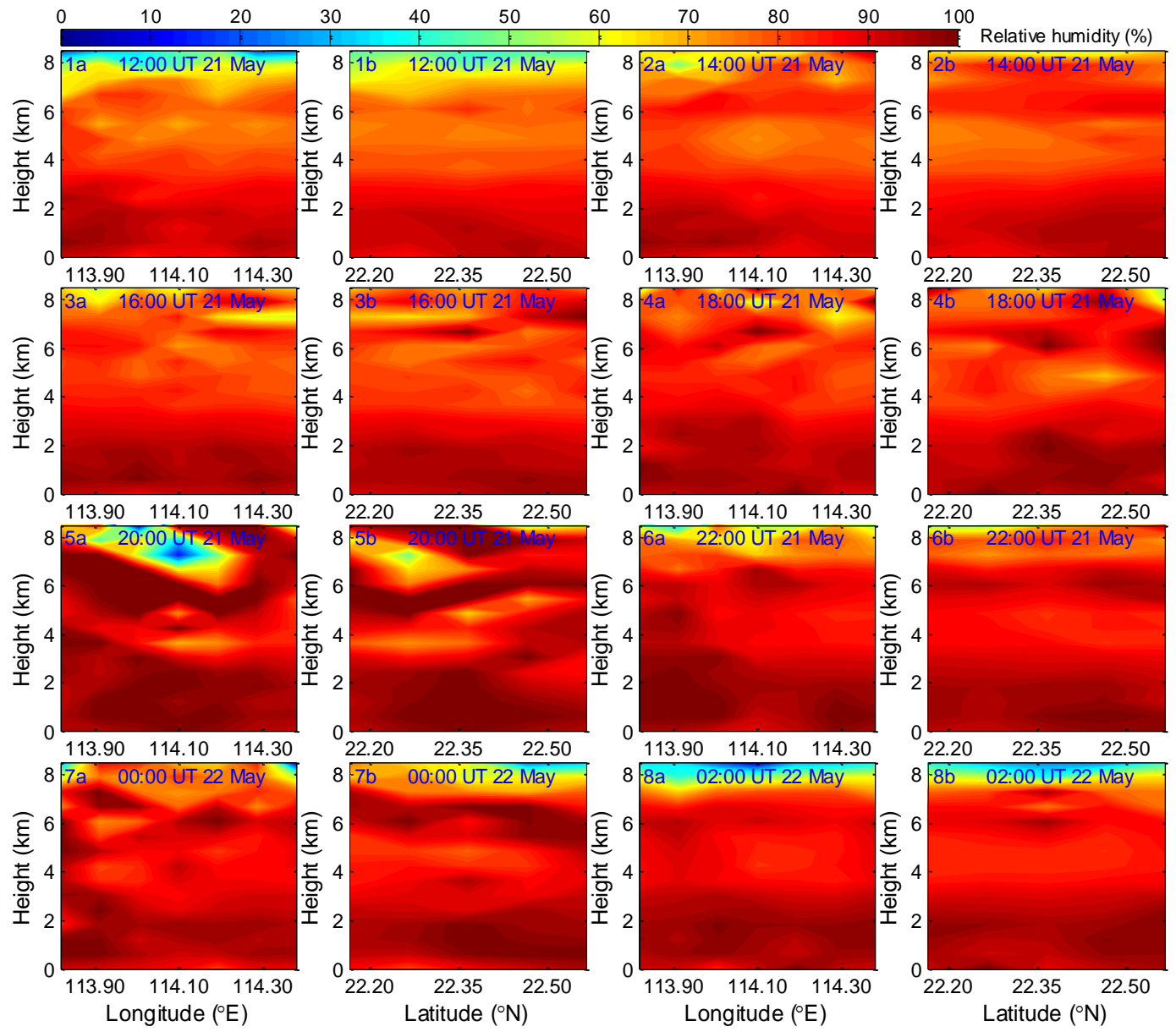

Figure 8. Evolution of tomographic relative humidity profiles every $2 \mathrm{~h}$ from 21 May 12:00 UT to 22 May 2013 02:00 UT. Subgraphs tagged with "a" refer to the relative humidity sections along the longitude of $114.17^{\circ}$ E. Subgraphs tagged with "b" refer to the relative humidity sections along the latitude of $22.30^{\circ} \mathrm{N}$. The longitude $114.17^{\circ} \mathrm{E}$ and latitude $22.30^{\circ} \mathrm{N}$ specify the location of the HKO weather station.

to $67 \%$, revealing the deficiency of tomography in retrieving the water vapor of high-altitude layers.

Water vapor tomography using the best tomographic scheme is further evaluated under heavy precipitation conditions in Hong Kong. Analysis results show that tomography performance during the rainstorm period is only slightly degraded compared to that in the whole evaluation period of May to October 2013. The tomography results during the 2122 May 2013 rainstorm show that atmospheric water vapor content increases prior to the occurrence of the rainstorm and decreases during the precipitation. This experiment indicates that the water vapor tomography result may make a contribution to the forecasting of severe weather conditions.

\section{Data availability}

The GNSS observations of SatRef were accessed from http://www.geodetic.gov.hk/smo/gsi/programs/ en/GSS/satref/satref.htm (HKSAR, 2014). The radiosonde data of Hong Kong were obtained from http://weather.uwyo.edu/upperair/sounding.html (University of Wyoming, 2013). The AERONET products were provided by http://aeronet.gsfc.nasa.gov (NASA, 2015). NWP and WVR data presented in this study are available from the authors upon request (1szzliu@polyu.edu.hk or by.chen@connect.polyu.hk).

Acknowledgements. This work is supported by the National Natural Science Foundation of China (No. 41274039), the Hong Kong Research Grants Council (RGC) Early Career Scheme Project (PolyU 5325/12E, F-PP0F), the General Research Fund Project (PolyU 5203/13E, B-Q37X) and the Hong Kong Polytechnic University project (PolyU 152168/15E, G-YBM3). The authors would like to appreciate the help of Wai Kin Wong, 
Wang Chun Woo, Sai Tick Chan and P. W. Chan from the Hong Kong Observatory, and the government of the Hong Kong Special Administrative Region (HKSAR) for providing the WVR and NWP data. The Lands Department of the government of the Hong Kong Special Administrative Region (HKSAR) and the Cartography and Cadastre Bureau (DSCC) of the government of the Macao Special Administrative Region (Macao SAR) are thanked for providing GNSS data for this work from the Hong Kong Satellite Positioning Reference Station Network (SatRef) and Macao Reference Network, respectively. The Department of Atmospheric Science of the University of Wyoming is acknowledged for providing the Hong Kong radiosonde data.

Edited by: S. Buehler

Reviewed by: two anonymous referees

\section{References}

Beckman, B.: A water-vapor radiometer error model, IEEE T. Geosci. Remote, GE-23, 474-478, 1985.

Bender, M. and Raabe, A.: Preconditions to ground based GPS water vapour tomography, Ann. Geophys., 25, 1727-1734, doi:10.5194/angeo-25-1727-2007, 2007.

Bender, M., Dick, G., Wickert, J., Ramatschi, M., Ge, M., Gendt, G., Rothacher, M., Raabe, A., and Tetzlaff, G.: Estimates of the information provided by GPS slant data observed in Germany regarding tomographic applications, J. Geophys. Res., 114, D06303, doi:10.1029/2008JD011008, 2009.

Bender, M., Dick, G., Ge, M., Deng, Z., Wickert, J., Kahle, H.-G., Raabe, A., and Tetzlaff, G.: Development of a GNSS water vapour tomography system using algebraic reconstruction techniques, Adv. Space Res., 47, 1704-1720, doi:10.1016/j.asr.2010.05.034, 2011.

Bevis, M., Businger, S., Herring, T. A., Rocken, C., Anthes, R. A., and Ware, R. H.: GPS meteorology: Remote sensing of atmospheric water vapor using the Global Positioning System, J. Geophys. Res.-Atmos., 97, 15787-15801, 1992.

Bi, Y., Mao, J., and Li, C.: Preliminary results of 4D water vapor tomography in the troposphere using GPS, Adv. Space Res., 23, 551-560, 2006.

Champollion, C., Masson, F., Bouin, M.-N., Walpersdorf, A., Doerflinger, E., Bock, O., and Van Baelen, J.: GPS water vapour tomography: preliminary results from the ESCOMPTE field experiment, Atmos. Res., 74, 253-274, doi:10.1016/j.atmosres.2004.04.003, 2005.

Champollion, C., Flamant, C., Bock, O., Masson, F., Turner, D. D., and Weckwerth, T.: Mesoscale GPS tomography applied to the 12 June 2002 convective initiation event of IHOP_2002, Q. J. Roy. Meteorol. Soc., 135, 645-662, doi:10.1002/qj.386, 2009.

Chan, K. and Li, C.: The Hong Kong Satellite Positioning Reference Station Network (SatRef) - System configurations, applications and services, Strategic Integration of Surveying Services, FIG Working Week 2007, Hong Kong, China, 13-17 May, 2007.

Chan, P. W.: The Use of Neural Network Retrieval for Thermodynamic Profiles of a Ground-based Microwave Radiometer, 11th Specialist Meeting on Microwave Radiometry and Remote Sensing of the Environment, Washington, DC, USA, 1-4 March, 2010 .
Chan, S. T., Chan, T. F., and Wong, W. K.: An intercomparison of WRF-ARW and JMA-NHM performance in prediction of tropical cyclones over the South China Sea in 2008, 29th Conference on Hurricanes and Tropical Meteorology, American Meteorological Society, available at: http://203.129.68.41/publica/ reprint/r887.pdf (last access: 29 October 2013), 2010.

Chen, B. and Liu, Z.: Voxel-optimized regional water vapor tomography and comparison with radiosonde and numerical weather model, J. Geod., 88, 691-703, doi:10.1007/s00190-014-0715-y, 2014.

Dach, R., Hugentobler, U., Fridez, P., and Meindl, M.: User manual of the Bernese GPS software version 5.0, Astronomical Institute, University of Bern, Bern, Switzerland, 2007.

Duan, J., Bevis, M., Fang, P., Bock, Y., Chiswell, S., Businger, S., Rocken, C., Solheim, F., van Hove, T., Ware, R., McClusky, S., Herring, T. A., and King, R. W.: GPS meteorology: direct estimation of the absolute value of precipitable water, J. Appl. Meteorol., 35, 830-838, 1996.

Elgered, G., Davis, J. L., Herring, T. A., and Shapiro, I. I.: Geodesy by radio interferometry: Water vapor radiometry for estimation of the wet delay, J. Geophys. Res.-Sol. Ea., 96, 6541-6555, 1991.

Elgered, G., Johansson, J. M., and Rönnäng, B. O.: Measuring regional atmospheric water vapor using the Swedish permanent GPS network, Geophys. Res. Lett., 24, 2663-2666, 1997.

Flores, A., Ruffini, G., and Rius, A.: 4D tropospheric tomography using GPS slant wet delays, Ann. Geophys., 18, 223-234, doi:10.1007/s00585-000-0223-7, 2000.

Gao, B. and Kaufman, Y. J.: Water vapor retrievals using Moderate Resolution Imaging Spectroradiometer (MODIS) near-infrared channels, J. Geophys. Res., 108, 4389, doi:10.1029/2002JD003023, 2003.

Giles, D. M., Holben, B. N., Eck, T. F., Sinyuk, A., Smirnov, A., Slutsker, I., Dickerson, R. R., Thompson, A. M., and Schafer, J. S.: An analysis of AERONET aerosol absorption properties and classifications representative of aerosol source regions, J. Geophys. Res.-Atmos. , 117, D17203, doi:10.1029/2012JD018127, 2012.

Guiraud, F. O., Howard, J., and Hogg, D. C.: A dual-channel microwave radiometer for measurement of precipitable water vapor and liquid, IEEE T. Geosci. Elect., 17, 129-136, 1979.

HKSAR: GNSS observation data, Lands Department of the Government of Hong Kong Special Administrative Region (HKSAR), available at: http://www.geodetic.gov.hk/smo/gsi/programs/en/ GSS/satref/satref.htm, last access: December 2014.

Holben, B. N., Eck, T. F., Slutsker, I., Tanré, D., Buis, J. P., Setzer, A., Vermote, E., Reagan, J. A., Kaufman, Y. J., Nakajima, T., Lavenu, F., Jankowiak, I., and Smirnov, A.: AERONET-A federated instrument network and data archive for aerosol characterization, Remote Sens. Environ., 66, 1-16, 1998.

Holben, B. N., Tanré, D., Smirnov, A., Eck, T. F., Slutsker, I., Abuhassan, N., Newcomb, W. W., Schafer, J. S., Chatenet, B., Lavenu, F., Kaufman, Y. J., Castle, J. V., Setzer, A., Markham, B., Clark, D., Frouin, R., Halthore, R., Karneli, A., O’Neill, N. T., Pietras, C., Pinker, R. T., Voss, K., and Zibordi, G.: An emerging ground-based aerosol climatology: aerosol optical depth from AERONET, J. Geophys. Res., 106, 12067-12097, 2001.

Jiang, P., Ye, S. R., Liu, Y. Y., Zhang, J. J., and Xia, P. F.: Near real-time water vapor tomography using ground-based GPS and 
meteorological data: long-term experiment in Hong Kong, Ann. Geophys., 32, 911-923, doi:10.5194/angeo-32-911-2014, 2014.

Kizilsu, G. and Sahin, M.: SLR precision analysis for LAGEOS I and II, Earth Planet. Space, 52, 789-794, 2000.

Kuo, Y.-H., Schreiner, W. S., Wang, J., Rossiter, D. L., and Zhang, Y.: Comparison of GPS radio occultation soundings with radiosondes, Geophys. Res. Lett., 32, L05817, doi:10.1029/2004GL021443, 2005.

Lee, S.-W., Kouba, J., Schutz, B., Kim, D. H., and Lee, Y. J.: Monitoring precipitable water vapor in real-time using global navigation satellite systems, J. Geod., 87, 923-934, doi:10.1007/s00190-013-0655-y, 2013.

Liu, Z. and Li, M.: The first PPP-based GPS water vapor real-time monitoring system in Pearl-River-Delta region, China, China Satellite Navigation Conference (CSNC) Proceedings, vol. 243, edited by: Sun, J., Jiao, W., Wu, H., and Shi, C., Springer Berlin Heidelberg, 71-87, doi:10.1007/978-3-642-37398-5_7, 2013.

Liu, Z., Wong, M. S., Nichol, J., and Chan, P. W.: A multi-sensor study of water vapour from radiosonde, MODIS and AERONET: a case study of Hong Kong, Int. J. Climatol., 33, 109-120, doi:10.1002/joc.3412, 2013a.

Liu, Z., Li, M., Zhong, W., and Wong, M. S.: An approach to evaluate the absolute accuracy of WVR water vapor measurements inferred from multiple water vapor techniques, J. Geodyn., 72, 86-94, doi:10.1016/j.jog.2013.09.002, 2013b.

Liu, Z., Chen, B., Chan, S. T., Cao, Y., Gao, Y., Zhang, K., and Nichol, J.: Analysis and modelling of water vapour and temperature changes in Hong Kong using a 40-year radiosonde record: 1973-2012, Int. J. Climatol., 35, 462-474, doi:10.1002/joc.4001, 2014.

Mohanakumar, K.: Stratosphere troposphere interactions: an introduction, Springer, New York, 42-44, 2008.

NASA: AERONET data, National Aeronautics and Space Administration (NASA), http://aeronet.gsfc.nasa.gov, last access: May 2015.

Niell, A. E.: Global mapping functions for the atmosphere delay at radio wavelengths, J. Geophys. Res.-Sol. Ea., 101, 3227-3246, 1996.

Niell, A. E., Coster, A. J., Solheim, F. S., Mendes, V. B., Toor, P. C., Langley, R. B., and Upham, C. A.: Comparison of measurements of atmospheric wet delay by radiosonde, water vapor radiometer, GPS, and VLBI, J. Atmos. Ocean. Tech., 18, 830-850, 2001.

Notarpietro, R., Cucca, M., Gabella, M., Venuti, G., and Perona, G.: Tomographic reconstruction of wet and total refractivity fields from GNSS receiver networks, Adv. Space Res., 47, 898-912, doi:10.1016/j.asr.2010.12.025, 2011.

Perler, D., Geiger, A., and Hurter, F.: 4D GPS water vapor tomography: new parameterized approaches, J. Geod., 85, 539-550, doi:10.1007/s00190-011-0454-2, 2011.

Rocken, C., Ware, R., Van Hove, T., Solheim, F., Alber, C., Johnson, J., Bevis, M., and Businger, S.: Sensing atmospheric water vapor with the global positioning system, Geophys. Res. Lett., 20, 2631-2634, 1993.

Rocken, C., Van Hove, T., and Ware, R.: Near real-time GPS sensing of atmospheric water vapor, Geophys. Res. Lett., 24, 32213224, 1997.

Rohm, W. and Bosy, J.: Local tomography troposphere model over mountains area, Atmos. Res., 93, 777-783, doi:10.1016/j.atmosres.2009.03.013, 2009.
Rohm, W. and Bosy, J.: The verification of GNSS tropospheric tomography model in a mountainous area, Adv. Space Res., 47, 1721-1730, doi:10.1016/j.asr.2010.04.017, 2011.

Rohm, W., Zhang, K., and Bosy, J.: Limited constraint, robust Kalman filtering for GNSS troposphere tomography, Atmos. Meas. Tech., 7, 1475-1486, doi:10.5194/amt-7-1475-2014, 2014.

Rüeger, J. M.: Refractive index formulae for radio waves, Proceedings of the FIG XXII International Congress, Washington, DC, USA, 1-13, 2002.

Saito, K.: Nonhydrostatic atmospheric models and operational development at JMA, J. Meteorol. Soc. Jpn., 85, 271-304, 2007.

Saito, K., Fujita, T., Yamada, Y., Ishida, J., Kumagai, Y., Aranami, K., Ohmori, S., Nagasawa, R., Kumagai, S., Muroi, C., Kato, T., Eito, H., and Yamazaki Y: The operational JMA nonhydrostatic mesoscale model, Mon. Weather Rev., 134, 1266-1298, 2006.

Shangguan, M., Bender, M., Ramatschi, M., Dick, G., Wickert, J., Raabe, A., and Galas, R.: GPS tomography: validation of reconstructed 3-D humidity fields with radiosonde profiles, Ann. Geophys., 31, 1491-1505, doi:10.5194/angeo-31-1491-2013, 2013.

Skone, S. and Hoyle, V.: Troposphere modeling in a regional GPS network, J. Glob. Position. Syst., 4, 230-239, 2005.

Smith, E. K. and Weintraub, S.: The constants in the equation for atmospheric refractive index at radio frequencies, J. Res. Natl. Bur. Stand., 50, 39-41, 1953.

Tregoning, P., Boers, R., O'Brien, D., and Hendy, M.: Accuracy of absolute precipitable water vapor estimates from GPS observations.pdf, J. Geophys. Res., 103, 28701-28710, 1998.

Troller, M., Geiger, A., Brockmann, E., Bettems, J.-M., Bürki, B., and Kahle, H.-G.: Tomographic determination of the spatial distribution of water vapor using GPS observations, Adv. Space Res., 37, 2211-2217, doi:10.1016/j.asr.2005.07.002, 2006.

University of Wyoming: Radiosonde data, Department of Atmospheric Science of the University of Wyoming, http://weather uwyo.edu/upperair/sounding.html, last access: February 2013.

Wang, J., Gopaul, N., and Scherzinger, B.: Simplified algorithms of variance component estimation for static and kinematic GPS single point positioning, J. Glob. Position. Syst., 8, 43-52, 2009.

Wen, D., Yuan, Y., Ou, J., Zhang, K., and Liu, K.: A Hybrid Reconstruction Algorithm for 3-D Ionospheric Tomography, IEEE T. Geosci. Remote, 46, 1733-1739, doi:10.1109/TGRS.2008.916466, 2008.

Wong, W. K.: Development of operational rapid update nonhydrostatic NWP and data assimilation systems in the Hong Kong Observatory, 3th International Workshop on Prevention and Mitigation of Meteorological Disasters in Southeast Asia, $1-4,2010$.

World Meteorological Organization: Guide to meteorological instruments and methods of observation, World Meteorological Organization, Geneva, Switzerland, 2008.

Xia, P., Cai, C., and Liu, Z.: GNSS troposphere tomography based on two-step reconstructions using GPS observations and COSMIC profiles, Ann. Geophys., 31, 1805-1815, doi:10.5194/angeo-31-1805-2013, 2013. 